\begin{tabular}{lcr}
\multicolumn{3}{c}{ ANNALES } \\
UNIVERSITATIS MARIAE CURIE-SKŁODOWSKA & \\
\multicolumn{3}{c}{ LUBLIN - POLONIA } \\
VOL. LXXI, 1 & SECTIO AA & 2016 \\
\hline
\end{tabular}

\title{
New trends in the reprocessing of spent nuclear fuel. Separation of minor actinides by solvent extraction
}

\author{
Jerzy Narbutt \\ Institute of Nuclear Chemistry and Technology, \\ Dorodna 16, 03-195 Warsaw, Poland \\ e-mail: j.narbutt@ichtj.waw.pl
}

\begin{abstract}
Recycling of actinides from spent nuclear fuel by their selective separation followed by transmutation in fast reactors will optimize the use of natural uranium resources and minimize the long-term hazard from high-level nuclear waste. This paper describes solvent extraction processes recently developed, aimed at the separation of americium from lanthanide fission products as well as from curium present in the waste. Depicted are novel poly$\mathrm{N}$-heterocyclic ligands used as selective extractants of actinide ions from nitric acid solutions or as actinide-selective hydrophilic stripping agents.
\end{abstract}

\section{INTRODUCTION}

Climate changes caused by greenhouse effect force us to a significant reduction in global emissions, in particular of $\mathrm{CO}_{2}$ (agreement on the UN Climate Change Conference, Paris, December 2015). Non-emitting nuclear energy has been successfully developed in numerous countries. In contrast, production of energy in Poland is based mainly on burning fossil fuels which - because of our geographical conditions - can hardly be replaced by renewable energy sources (wind, hydro, solar). The only real option for our country is to develop an energy mix with a significant 
contribution from the zero-emission nuclear energy (Polish Nuclear Energy Program, 2014).

The biggest disadvantage of nuclear energy is the possibility of a major radioactive incident caused by strongly radiotoxic long-lived nuclear waste produced during operation of nuclear power plants. This potential long-term threat to humans and the environment must be reduced to the minimum. To meet this challenge, extensive research is being carried out worldwide on improving the present technologies of reprocessing of spent nuclear fuel (SNF), focused on a drastic reduction of the radiotoxicicity of the nuclear waste by closing nuclear fuel cycle. These endeavors are an important element of the long-term sustainability of nuclear energy.

The aim of this review is the presentation of European activities directed on solving the chemical issues of advanced reprocessing of SNF. The results of related $R \& D$ and fundamental works in the field of solvent extraction separation of minor actinides from the nuclear wastes have been presented and discussed.

\section{REPROCESSING OF SPENT NUCLEAR FUEL AND SUSTAINABILITY OF NUCLEAR ENERGY}

Since the mid of the XX century the main reason for reprocessing SNF has been to recover plutonium, along with unused uranium, thereby partly close the fuel cycle, gaining by a quarter more energy from the original uranium in the process. The other reason is to reduce the volume of material to be disposed of as high-level waste by a factor of five, to reduce the heat generation from the waste, and to shorten (from over $2 \cdot 10^{5}$ to ca. $10^{4}$ years) the period in which radiotoxicity ${ }^{*}$ of the nuclear waste is greater than that of the corresponding amounts of natural uranium ore.

\subsection{Recycling of plutonium and uranium}

The hydrometalurgical technology universally employed for reprocessing spent nuclear fuel, the PUREX (Plutonium Uranium Redox

\footnotetext{
* Radiotoxicity may be defined as a measure of the biological hazard i.e. of the damage to living tissue caused by incorporated radionuclides and their daughters, dependent on the nature and energy of the emitted ionizing radiation as well as on its effect on the tissue.
} 
EXtraction) process, is based on solvent extraction of U(VI) and $\mathrm{Pu}(\mathrm{IV})$ from strongly acidic nitrate SNF solutions using tributyl phosphate (TBP) dissolved in an aliphatic diluent [1]. Most of the nonvolatile fission products and the minor actinides $(\mathrm{MA}=$ neptunium, americium, curium etc.) remain in the aqueous raffinate. The reprocessed plutonium and uranium are being recycled into a mixed oxide (MOX) fuel $\left(\mathrm{UO}_{2}\right.$ and $\mathrm{PuO}_{2}$ ) which can be used in thermal reactors. The separated uranium needs to be enriched, whereas plutonium goes straight to the fuel fabrication. Recent modifications of the PUREX process make it possible to separate also neptunium and long-lived fission products, in particular technetium-99 and iodine-129, but no reasonable modification allows to separate the trivalent MA, americium and curium, which remain in the aqueous phase and cause the radiotoxicity of the nuclear waste still high and long-lasted [1].

However, nowadays as much as about $90 \%$ of nuclear reactors worldwide operate on a once-through fuel cycle (open fuel cycle) leaving unprocessed the huge volumes of spent uranium-oxide fuel as nuclear waste. This dominated part of the global SFN inventory is being temporarily stored until a final solution of the problem. The solution is expected with moving to fast neutron reactors of fourth-generation when the large stockpiles of the spent fuel should become a source of new fuel. The fast reactors will ensure the efficient burning of plutonium, which is incomplete in thermal reactors of today.

According to the statement of the American Nuclear Society, "the development and deployment of advanced nuclear reactors based on fastneutron fission technology is important to the sustainability, reliability and security of the world's long-term energy supply ... thereby extending by a hundred-fold the amount of energy extracted from the same amount of mined uranium ... virtually all long-lived heavy elements are eliminated during fast reactor operation, leaving a small amount of fission product waste which requires assured isolation from the environment for less than 500 years" [2]. Moreover, plutonium added as MOX or created during fast reactor operation will be consumed and reprocessed on-site increasing proliferation resistance of the fuel cycle.

This is not so with plutonium from thermal reactor fuels, separated using the PUREX process. In order to reduce the chance of illicit use of pure plutonium preparations attempts were undertaken to develop new proliferation-resistant recycling technologies. To achieve this goal modifications are being introduced to the PUREX process, preventing the separation of pure plutonium. For example, the COEX (CO-EXtraction of 
actinides) process developed in France leaves certain amounts of recovered uranium with the plutonium which is sent to the MOX fuel fabrication [3]. This has been done by subtle changes in the PUREX chemistry, that cause back co-extraction of small amounts of processed uranium together with plutonium from the loaded organic phase, followed by co-precipitation of uranium and plutonium (and possibly neptunium) as a mixed oxide, $(\mathrm{U}, \mathrm{Pu}) \mathrm{O}_{2}$, beside the pure uranium stream, eliminating any separation of plutonium on its own [4].

\subsection{Recycling of minor actinides}

Further reduction of radiotoxicity and the heat load of the highly radioactive nuclear waste can be achieved using advanced techniques for MA separation. Therefore, at the end of XX century interest grown in recovering not only plutonium but also the long-lived minor actinides, to transmute them in fast reactors into short-lived fission products. The details will be the subject of the next sections of the paper. Nonetheless, the removal from the SNF of all actinides, including MA, leaving much less volumes of relatively short-lived fission products in the waste will allow to consider the fuel cycle closed. This will further shorten the period of high radiotoxicity of the remaining nuclear waste to no more that ca. 300 years.

According to the strategy of Partitioning and Transmutation (P\&T), the separated ('partitioned') actinides will be transmuted into much shorter-lived and stable nuclides by high energy (fast) neutrons, e.g. in fast nuclear reactors of Generation IV [5]. Therefore, the advanced closed fuel cycles based on P\&T will contribute to the long-term sustainability of nuclear energy. The major benefits from the optimized recycling of actinides would be not only a significant reduction of the volume, heat load and long-term radiotoxicity of the highly radioactive nuclear waste, but also a more efficient use of the fissionable material instead of being finally disposed of, thus minimizing uranium consumption. Such a solution is expected by emerging concerns about exhaustion of natural resources, that highlight the effect of energy security issues on sustainability, and stress the importance of fuel diversification [6].

An important contribution to the sustainability is the safety of the recycling processes. The safety aspects of the newly developed hydrometallurgical and pyrometallurgical processes of actinide separation [7] are the subject of ongoing studies within the European FP7 collaborative project SACSESS (Safety of ACtinide SEparation proceSSes) [8], the continuation and extension of the previous Euratom 
project ACSEPT (Actinide reCycling by SEParation and Transmutation) [7]. The pyrometallurgical technologies of SNF reprocessing (including electrometallurgical processes), alternative to the dominating hydrometallurgical ones, enable selective extraction of actinides from molten salts or liquid metals, based on different redox and acido-basic properties of the separated metals $[9,10]$. These high-temperature methods have certain advantages especially in the case of reprocessing fuels from molten salt reactors [1]. However, there is still little demand for new pyrometallurgical systems, therefore they are no more discussed in the present paper Also some other issues of primary importance for the safety of nuclear fuel cycles associated with the P\&T strategy, in particular radiolytic stability of solvent extraction systems used for SNF reprocessing as well as manufacturing and reprocessing new types of mixed oxide fuels (MOX) containing also minor actinides (for Generation IV reactors), have been discussed elsewhere [8]. The scope of the present review is limited to hydrometallurgical separations of actinides from spent nuclear fuels by using solvent extraction methods.

\section{SOLVENT EXTRACTION SEPARATION OF MINOR ACTINIDES FROM LANTHANIDES}

The indispensable condition for MA transmutation to be efficient is the initial separation of MA from fission products (FP) of high neutron cross sections, which act as reactor poisons and decrease the efficiency of the transmutation. The presence in SNF of significant amounts of certain lanthanide isotopes which are reactor poisons is a problem for chemists. This is because the similarity of chemical properties of trivalent actinides and lanthanides makes their separation not an easy task. The separation of $\mathrm{An}^{\mathrm{III}}$ from $\mathrm{Ln}^{\mathrm{III}}$ by solvent extraction, i.e. in two-phase (organic/aqueous) hydrometallurgical systems, was the subject of numerous reviews, in particular [11-13]. There exist, actually, extractants that enable very selective separation of these f-electron elements. Their selectivity for $A n^{\text {III }}$ ions 'softer' (according to Pearson's HSAB concept) than $\mathrm{Ln}^{\text {III }}$ ones, is due to the presence of 'soft' donor sulfur atoms in the molecule. For example, bis(2,4,4-trimethylpentyl)-dithiophosphinic acid, the main component of a commercial extractant CYANEX 301, has a very high $\mathrm{Am}^{\mathrm{III}} / \mathrm{Eu}{ }^{\mathrm{III}}$ separation factor, $\mathrm{SF}_{\mathrm{Am} / \mathrm{Eu}}=\mathrm{D}_{\mathrm{Am}} / \mathrm{D}_{\mathrm{Eu}} \approx 5 \cdot 10^{3}$ in a toluene/aqueous nitrate system at $\mathrm{pH}>3\left(\mathrm{D}_{\mathrm{M}}\right.$ denotes the distribution ratio of $\mathrm{M}^{3+}$ ), and in the presence of a synergist as 2,2'-bipyridine or 1,10-phe- 
nantroline the $\mathrm{SF}_{\mathrm{Am} / \mathrm{Eu}}$ value exceeds $40 \cdot 10^{3}$ [14]. However, such ligands that efficiently complex the metal ions only at relatively high $\mathrm{pH}$ are useless when extraction of these metals from strongly acidic nitrate SNF solutions is expected. Moreover, to avoid formation of secondary solid radioactive waste that form when burning spent solvents, the current strategies of SNF reprocessing rely on the use of such extraction systems whose components are completely incinerable i.e. contain only atoms of carbon, hydrogen, oxygen and nitrogen [12]. This 'CHON' principle makes the extractants containing also the $\mathrm{P}$ and $\mathrm{S}$ atoms inconvenient for technology.

\subsection{An III L LnII separations using actinide-selective bis-triazinyl extractants}

Lipophilic tri-N-dentate ' $\mathrm{CHON}$ ' ligands which eagerly extract trivalent f-electron metal ions from acidic aqueous solutions, bis-triazinylpyridines (BTP, Fig. 1a), are known as extractants selective for $\mathrm{An}^{\mathrm{III}}$ over $\mathrm{Ln}^{\mathrm{III}}$ ions for nearly two decades [15]. Newly synthesized 6,6'-bis (5,5,8,8-tetramethyl-5,6,7,8-tetrahydro-benzo[1,2,4]triazin-3-yl[2,6]pyridine (CyMe $\mathrm{C}_{4}$-BTP) molecule [16], stable against hydrolysis, demonstrated very high selectivity $\left(\mathrm{SF}_{\mathrm{Am} / \mathrm{Eu}}>1000\right)$, but too high $\mathrm{D}_{\mathrm{Am}}$ values caused problems with the metal recovery from the organic phase by stripping [12]. They have been solved by the synthesis of similar ligand molecules, tetra-N-dentate bis-triazinyl-bipyridines (BTBP) [17]. One of the ligands, 6,6'-bis(5,5,8,8-tetramethyl-5,6,7,8-tetrahydro-benzo[1,2,4]triazin-3-yl[2, 2']bipyridine (CyMe ${ }_{4}$-BTBP, Fig. 1b) sufficiently stable against hydrolysis and radiolysis [18], has been selected the European reference molecule for the development of the $A n^{\text {III }} / \mathrm{Ln}^{\text {III }}$ separation process SANEX [13]. 
(a)

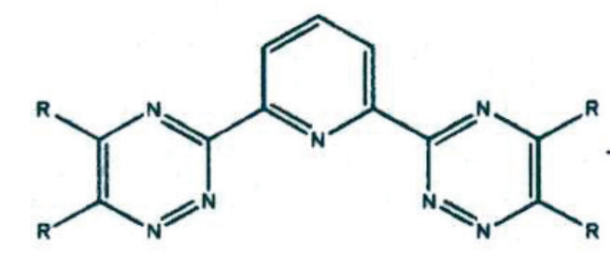

(b)

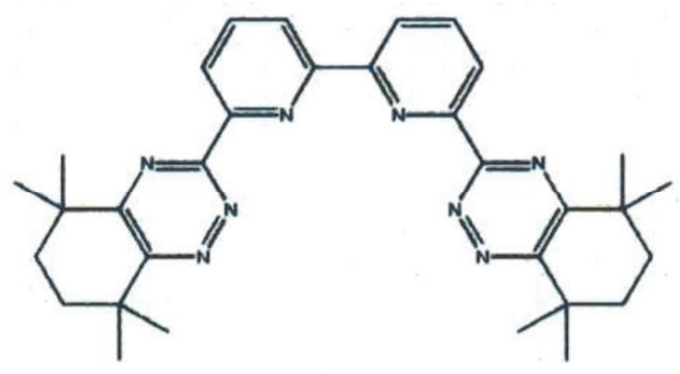

(c)

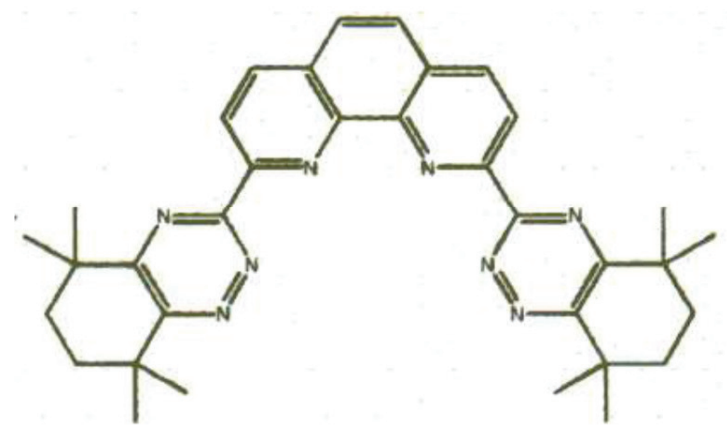

Fig. 1. Structural formulae of bis-triazinyl ligands: (a) R-BTP (R - aliphatic group), (b) $\mathrm{CyMe}_{4}-\mathrm{BTBP}$ and (c) $\mathrm{CyMe}_{4}-\mathrm{BTPhen}$.

The BTP and BTBP ligands (L) dissolved in an organic diluent, usually kerosene or kerosene/1-octanol mixtures, extract the $\mathrm{M}^{3+}$ ions $(\mathrm{M}=\mathrm{An}$ or $\mathrm{Ln})$ from aqueous $\mathrm{HNO}_{3}$ solutions by forming strong cationic $\left[\mathrm{M}(\mathrm{BTP})_{3}\right]^{3+}$ and $\left[\mathrm{M}(\mathrm{BTBP})_{2}\left(\mathrm{NO}_{3}\right)\right]^{2+}$ complexes which are transfered to the organic phase as neutral salts with nitrate counter ions. Also neutral $\left[\mathrm{M}(\mathrm{BTBP})\left(\mathrm{NO}_{3}\right)_{3}\right]$ complexes can be extracted. The ligands of low $\mathrm{p} K_{a}$ values either are not protonated in the system or deprotonate upon complex formation. The complexes are formed in the interphase, therefore the extraction kinetics is slow. It can be accelerated by adding to the system a phase-transfer agent, lipophilic but slightly soluble in the aqueous phase, in particular $N, N^{\prime}$-dimethyl- $N, N^{\prime}$-dioctyl-2-(2-hexyloxyethyl)malonamide (DMDOHEMA) [19] or $N, N, N^{\prime}, N^{\prime}$-tetraoctyldiglycolamide (TODGA) [20] (Fig. 2). The phase-transfer agents in suitably selected concentrations slightly $\left(D_{M}<<1\right)$ transfer the $\mathrm{M}^{3+}$ ions to the organic phase where the M-L complexes are easily formed. The kinetics of $\mathrm{M}^{3+}$ extraction by BTBPs is accelerated also by certain diluents, in particular cyclohexanone [21]. We have noticed that in these biphasic systems cyclohexanone acts exactly as the phase-transfer agent for the $\mathrm{M}^{3+}$ ions [22]. 


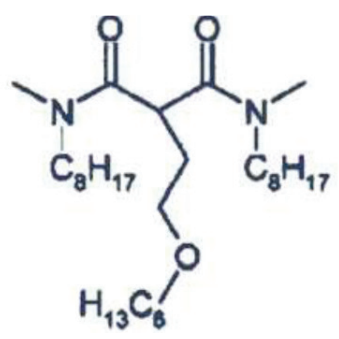

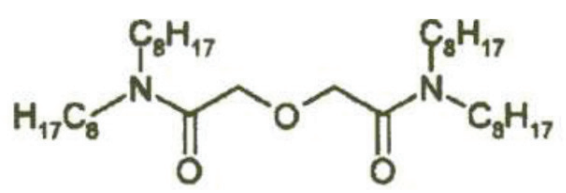

Fig. 2. Structural formulae of DMDOHEMA (left) and TODGA (right) ligands.

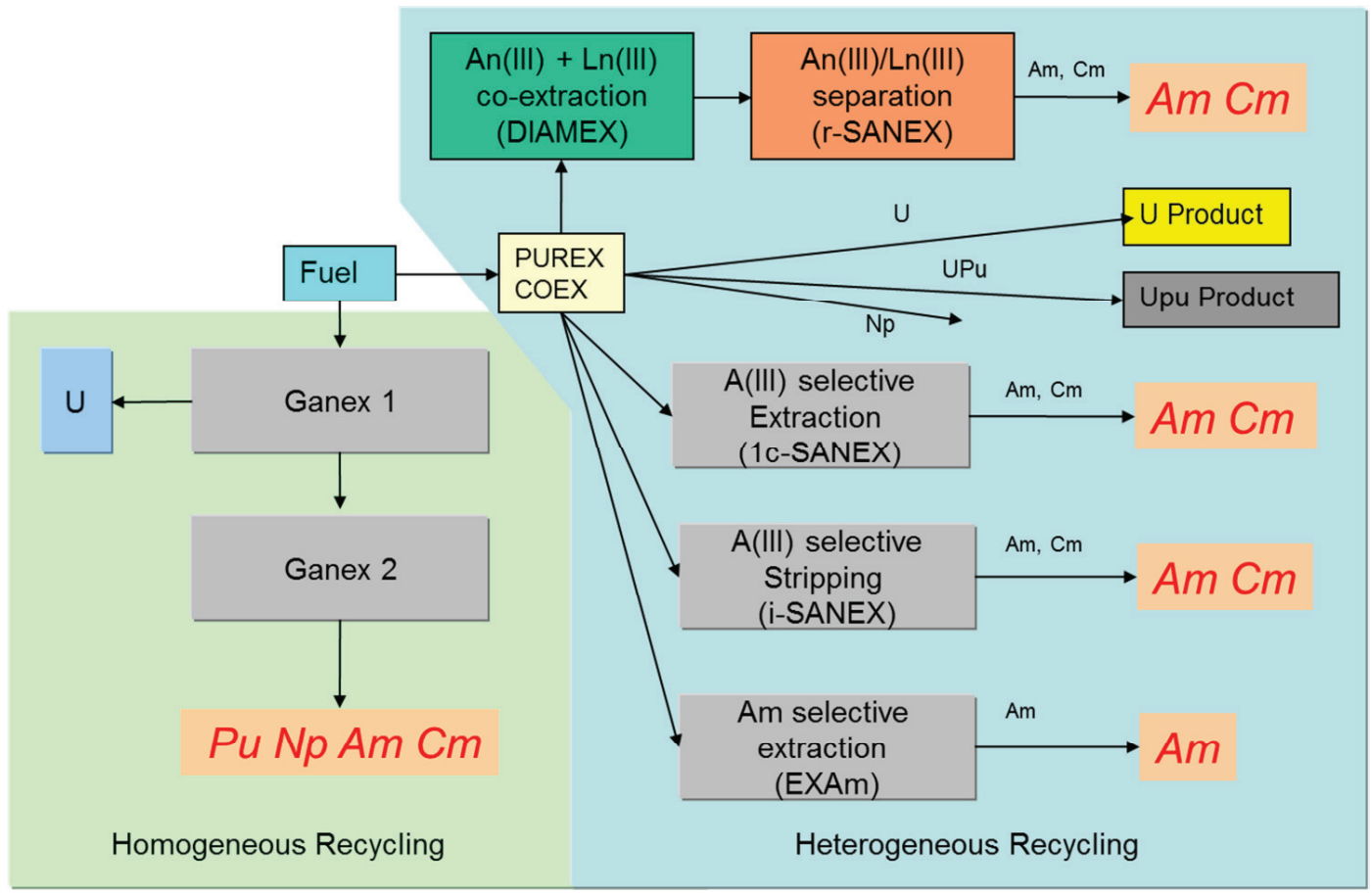

Fig. 3. Hydrometallurgical processes studied in ACSEPT and SACSESS projects. (Reprinted from the Ref. [8], with the permission from the Editor of Nukleonika.)

The SANEX (Selective ActiNide EXtraction) process assumes the MA extraction with $\mathrm{CyMe}_{4}$-BTBP to be accomplished from the aqueous $\mathrm{HNO}_{3}$ solution containing only trivalent ions of MA and lanthanide fission products already removed from the PUREX raffinate by nonselective extraction using a malonamide extractant (the DIAMEX process [1, 23], Fig. 3). Preliminary studies on the system were carried out with the convenient ${ }^{152} \mathrm{Eu}$ and ${ }^{241} \mathrm{Am}$ radiotracers. $\mathrm{Eu}^{3+}$, one of the best extracted $\mathrm{Ln}^{3+}$ ions, is generally used in the experiments on the $\mathrm{An}{ }^{\mathrm{III}} / \mathrm{Ln}^{\mathrm{III}}$ separations as the representative of $\mathrm{Ln}^{3+}$. Because of rather poor solubility of $\mathrm{CyMe}_{4}-\mathrm{BTBP}$ in kerosene/1-octanol diluents, practically the only adjustable parameter to obtain efficient separation $\left(\mathrm{D}_{\mathrm{Am}}>1\right.$ and $\left.\mathrm{D}_{\mathrm{Eu}}<1\right)$ 
is the $\mathrm{HNO}_{3}$ concentration. High separation factor values, $\mathrm{SF}_{\mathrm{Am} / \mathrm{Eu}} \approx 150$, have been found in these extraction systems, slightly dependent on their composition [19]. The results of batch laboratory experiments aimed on the MA recovery from PUREX raffinate require further demonstrations of the practical usability of the new flow-sheets of extraction processes. A review has been published of the counter-current tests carried out in multistage centrifugal contactors [23]. A series of such spiked tests and 'hot' tests (with a genuine fuel solution in $2 \mathrm{M} \mathrm{HNO}_{3}$ ) of the regular SANEX (r-SANEX) process confirmed the usability of $\mathrm{CyMe}_{4}$-BTBP extractant for large scale separation of ${ }^{241} \mathrm{Am}$ and ${ }^{244} \mathrm{Cm}$ from the lanthanide fission products [20, 24, 25].

In order to improve the slow kinetics of $\mathrm{M}^{3+}$ extraction, observed for the BTBPs [13,19], a novel lipophilic ligand of partly preorganized structure of the molecule, 2,9-bis(5,5,8,8-tetramethyl-5,6,7,8-tetrahydrobenzo-1,2,4-triazin-3-yl)-1,10-phenantroline

$\left(\mathrm{CyMe}_{4}-\mathrm{BTPhen}\right.$, Fig. 1c) [26]. It was expected that to achieve the cis-cis conformation of the pyridine groups in the BTBPs, that is required to form a complex, a significant energy barrier to rotation around the central biaryl $\mathrm{C}-\mathrm{C}$ axis must be overcome, while this conformation is already fixed in the BTPhens [26, 27]. Recent QM calculations on the conformations of the $\mathrm{CyMe}_{4}-\mathrm{BTBP}$ molecule show that just the rotation around the central $\mathrm{C}-\mathrm{C}$ bond is decisive on the energy gain following the conversion from the most stable $t t t$ conformer, while the rotations around the $\mathrm{C}-\mathrm{C}$ bonds connecting the pyridine and triazine groups, leading to the $c c c$ conformer require much less energy [28]. Accordingly, not only the kinetics of $\mathrm{Am}^{3+}$ and $\mathrm{Eu}^{3+}$ extraction with $\mathrm{CyMe}_{4}-\mathrm{BTPhen}$ was significantly faster than that with $\mathrm{CyMe}_{4}$-BTBP, but also the respective $\mathrm{D}_{\mathrm{Am}}, \mathrm{D}_{\mathrm{Eu}}$ and $\mathrm{SF}_{\mathrm{Am} / \mathrm{Eu}}$ values determined under comparable conditions appeared significantly higher for $\mathrm{CyMe}_{4}$-BTPhen [26,27] than for $\mathrm{CyMe}_{4}-\mathrm{BTBP}$ [19].

In order to simplify the complex multicycle procedure of actinide partitioning from PUREX raffinate based on the DIAMEX and r-SANEX processess, attempts were undertaken to reduce the number of cycles and to develop a process of selective extraction of trivalent actinides directly from the PUREX raffinate. The same $\mathrm{CyMe}_{4}$-BTBP extractant and TODGA as the phase-transfer agent were used to extract MA from $3 \mathrm{M}$ $\mathrm{HNO}_{3}$, while co-extracting fission and corrosion products $(\mathrm{Pd}, \mathrm{Zr}$, Mo etc.) were masked in the feed by oxalic acid and other hydrophilic complexants [29]. The developed 1cycle-SANEX process (Fig. 3) was then successfully tested in a battery of centrifugal contactors [30]. 


\subsection{Reasons of the actinide selectivity of bis-triazinyl ligands}

The actinide selectivity of BTBP extractants is due to the formation of stronger, more covalent complexes with $\mathrm{An}^{3+}(\mathrm{Am}$ and $\mathrm{Cm}$ ) than with $\mathrm{Ln}^{3+}$ ions [13]. This is commonly interpreted in terms of more favorable interactions of fairly 'soft' BTBP ligands with the $\mathrm{Am}^{3+}$ cation somewhat 'softer' than $\mathrm{Eu}^{3+}$, however, there is no generally accepted view what is the origin of this difference, in particular which metal orbitals mainly contribute to the bonding and why [31].

Our recent quantum mechanical (QM) studies on BTBP complexes of $\mathrm{Am}^{3+}$ and $\mathrm{Eu}^{3+}$ ions confirm that the higher covalency of the Am-N than $\mathrm{Eu}-\mathrm{N}$ bonds results from a greater electron density transfer from the ligands to the $\mathrm{Am}^{3+}$ than $\mathrm{Eu}^{3+}$ ions, causing a greater electron population on the $6 \mathrm{~d}$ orbital of $\mathrm{Am}^{3+}$ than on the 5d orbital of $\mathrm{Eu}^{3+}$ ion $[32,33]$. This greater electron transfer resulting in Am-selectivity of BTBP ligands is probably connected with different overlaps of lone pair orbitals on the donor nitrogen atoms of the ligands with acceptor orbitals on the metal ions, which is greater for $6 \mathrm{~d}\left(\mathrm{Am}^{3+}\right)$ than for $5 \mathrm{~d}\left(\mathrm{Eu}^{3+}\right)$ orbital, because of a greater spatial range of the former [33]. On the contrary, QM studies by Shi et al. on the corresponding BTPhen complexes of $\mathrm{Am}^{3+}$ and $\mathrm{Eu}^{3+}$ show that the difference in electron population on the $5 \mathrm{f}\left(\mathrm{Am}^{3+}\right)$ and $4 \mathrm{f}$ $\left(\mathrm{Eu}^{3+}\right)$ orbitals plays the dominant role in respect to the Am-selectivity of BTPhen ligands [34].

\section{3. $A n^{I I I} / \mathrm{Ln}^{I I I}$ separations using hydrophilic actinide-selective bis-} triazinyl ligands

Another new process aimed at a simplification of the DIAMEX/ /r-SANEX approach consists in the selective back-extraction (stripping) of An(III) from the loaded organic phase of the DIAMEX process, in particular containing TODGA which co-extracts $\mathrm{An}^{3+}$ and $\mathrm{Ln}^{3+}$ ions [35]. The actinide-selective stripping agent is a hydrophilic sulfonated derivative of BTP, 2,6-bis(5,6-di-(sulfophenyl)-1,2,4-triazin-3-yl-)pyridine in the anionic form $\left(\mathrm{SO}_{3}-\mathrm{Ph}-\mathrm{BTP}^{4-}\right.$, Fig. 4). This innovativeSANEX process (i-SANEX, Fig. 3) has also been tested in a multistage counter-current system [36]. 


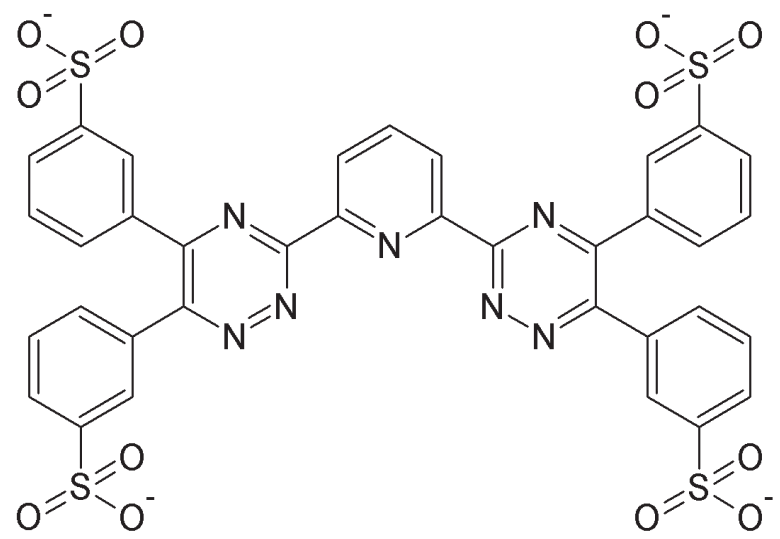

Fig. 4. Structural formula of the $\mathrm{SO}_{3}-\mathrm{Ph}-\mathrm{BTP}^{4-}$ anion. (Reprinted from Ref. [39] with the permission from the Editor of Nukleonika.)

The knowledge of complexing properties of novel ligands to be used in solvent extraction processes allows us to predict the usefulness of these ligands for designing new separation schemes. Solvent extraction studies by Geist et al., carried out with the system TODGA/ $\mathrm{SO}_{3}-\mathrm{Ph}-\mathrm{BTP}$ $+\mathrm{HNO}_{3}$, suggested the presence of only two (1:1 and 1:2) $\mathrm{Am}^{3+}-\mathrm{SO}_{3}-$ $\mathrm{Ph}-\mathrm{BTP}$ complexes in the aqueous phase [35]. Though no stability constants of these complexes have been found in literature, such data are available for the respective complexes of $\mathrm{Cm}^{3+}$ (whose chemical properties are very similar to those of $\mathrm{Am}^{3+}$, but which can be studied using time-resolved laser fluorescence spectroscopy, TRLFS). Using this technique Geist et al. have found not two but three $(1: 1-1: 3) \mathrm{Cm}^{3+}$ $\mathrm{SO}_{3}-\mathrm{Ph}-\mathrm{BTP}^{4-}$ complexes in aqueous solutions and determined their stability constants [37]. In order to understand why the 1:3 complex had not been observed in the solvent extraction system, we determined the number and stoichiometry of the $\mathrm{Am}^{3+}-\mathrm{SO}_{3}-\mathrm{Ph}-\mathrm{BTP}^{4-}$ complexes in the acidic $\left(\mathrm{HNO}_{3}\right)$ aqueous phase of a two-phase system, and calculated the stability constants of the complexes in the presence of two competing ligands: hydrophilic $\mathrm{SO}_{3}-\mathrm{Ph}-\mathrm{BTP}^{4-}$ in the aqueous phase and lipophilic TODGA in the organic phase of the system studied. Only two $\mathrm{Am}^{3+}$ complexes (1:1 and 1:2) were found in the broad range of $\mathrm{SO}_{3}-\mathrm{Ph}-\mathrm{BTP}^{4-}$ concentrations studied, moreover, of distinctly lower stability constants than those of the respective $\mathrm{Cm}^{3+}$ complexes which had been determined in the single aqueous phase (without TODGA) [38]. Because of that, we have presented a hypothesis that lipophilic heteroleptic complexes can be formed in the two-phase system, for example [Am(TODGA) ${ }_{2}\left(\mathrm{SO}_{3}-\mathrm{Ph}\right.$ $\mathrm{BTP})]^{-}$extractable as an ion pair with protonated extractant $\left(\mathrm{TODGA} \cdot \mathrm{H}^{+}\right)$ 
from the acidic aqueous phase [38]. The search of such hypothetical species has already been started. It is worth mentioning that also two uranyl $-\mathrm{SO}_{3}-\mathrm{Ph}-\mathrm{BTP}^{4-}$ complexes $(1: 1$ and 1:2) of lower stability have been detected in similar solvent studies [39].

Also other hydrophilic sulfonated bis-1,2,4-triazine ligands, the derivatives of BTBP and BTPhen [40,41], as well as some completely incinerable CHON ligands [42-44] appeared effective complexing reagents for separating actinides(III) from lanthanides(III) via selective formation of aqueous actinide complexes, the sulfonated ligands being more efficient.

The $\mathrm{SO}_{3}-\mathrm{Ph}-\mathrm{BTP}^{4-}$ ligand in a combination with acetohydroxamic acid (AHA) has been proposed and tested as a stripping agent, very efficient for plutonium and americium recovery in the alternative 2nd cycle of the GANEX (Group ActiNide EXtraction) process [45-47]. GANEX, replacing PUREX and its supplementary processes (Fig. 3), is aimed at the homogenous recycling of actinides by co-extraction of transuranium elements $(\mathrm{Np}, \mathrm{Pu}, \mathrm{Am}, \mathrm{Cm})$ in the oxidation states III, IV, VI and possibly $\mathrm{V}$ from strongly acidic $\left(\mathrm{HNO}_{3}\right)$ solutions of SNF. After SFN dissolution of SFN in concentrated $\mathrm{HNO}_{3}$ and selective extraction of bulk uranium(VI) using e.g. di-2-ethylhexyl-izobutylamide (the 1st cycle), the remaining An ions are co-extracted in the 2nd cycle. Hydrophilic complexants are used to prevent co-extraction of certain fission and corrosion products. Various combinations of the actinide extractants were studied [21,45]; the recent variant of the 2nd cycle, the „EURO-GANEX” process is based on the combination of TODGA and DMDOHEMA [46,47].

\section{3. $\mathrm{Am}^{I I I} / \mathrm{Cm}^{I I I}$ separation}

French expertise in the SNF reprocessing allows us to limit the number of long-lived MA which should be transmuted to americium merely [48]. The presence of curium in the fuel fabrication is undesirable because the high neutron dose and heat generation from curiumcontaining transmutation targets would require special shielding at any step of the fuel cycle [49]. On the other hand, the short half-life (18 y) of the major isotope ${ }^{244} \mathrm{Cm}$ makes possible disposal of curium together with the fission products. This implies the necessity to separate Am ${ }^{\text {III }}$ not only from chemically similar lanthanide fission products, but also from much more similar $\mathrm{Cm}^{\mathrm{III}}$. The latter is not an easy task however, because the $\mathrm{SF}_{\mathrm{Am} / \mathrm{Cm}}$ values in common extraction systems used in recycling technologies are low, e.g. in the DMDOHEMA / $\mathrm{HNO}_{3}$ system $\mathrm{SF}_{\mathrm{Am} / \mathrm{Cm}} \approx 1.6$, 
which requires a large number of steps in counter-current separation processes [49]. The separations based on the oxidation of $\mathrm{Am}^{\mathrm{III}}$ to $\mathrm{Am}^{\mathrm{VI}}$ are less prospective because of chemical instability of higher oxidation states of americium [50].

Efficient separation of $\mathrm{Am}^{\mathrm{III}}$ from $\mathrm{Cm}^{\mathrm{III}}\left(\mathrm{SF}_{\mathrm{Am} / \mathrm{Cm}}>8\right)$ has been reached by extraction from dilute $\mathrm{HNO}_{3}$ solutions into the synergistic mixture of bis(chlorophenyl)dithiophosphinic acid and tris(2ethylhexyl)phosphate in tert-butylbenzene [51]. The LUCA (Lanthaniden Und Curium/Americium Trennung) counter-current separation process based on this method was developed and tested in Germany [52], but the $\mathrm{HNO}_{3}$ concentrations required for so efficient separation were too low for the practical purposes, and the sulphur-containing extractants (not $\mathrm{CHON}$ solvents) were not the best option.

Another process for single Am recycling from highly acidic PUREX or COEX raffinates, the EXAm process (EXtraction of Americium, Fig. 3) developed in France, improves the weak selectivity of the DMDOHEMA + di-2-ethylhexylphosphoric acid / $\mathrm{HNO}_{3}$ system by adding to the aqueous phase a curium-selective hydrophilic complexing agent, $\quad N, N, N^{\prime}, N^{\prime}$-tetraethyl-diglycolamide (TEDGA), a homolog of TODGA (Fig. 2), the presence of which rises the $\mathrm{SF}_{\mathrm{Am} / \mathrm{Cm}}$ value to about 2.5 [53]. The 'hot' test (on a genuine PUREX raffinate) of the countercurrent process consisting of 68 mixer-settler stages (extractionscrubbing-stripping) was carried out, resulting in the americium recovery over $98 \%$ with a high decontamination of Am from Cm [49]. Recent studies by Marie et al. have shown that TEDGA is the most efficient Am/Cm separating agent among the diglycolamides of short side-chains lengths (methyl to butyl), and moreover pointed to a possible formation of extractable mixed solvates $\mathrm{Ln}\left(\mathrm{NO}_{3}\right)_{3}-(\text { TEDGA })_{n}$-DMDOHEMA $(\mathrm{n}=1,2)$ as a reasonable interpretation of the observed co-extraction of TEDGA with the lightest lanthanides [54]. The existence of such mixed-ligand complexes of the lightest lanthanides had already been postulated by Pacary et al. who modeled the EXAm system [55]. These suggestions well correspond to our recent hypothesis on the formation of the extractable lipophilic heteroleptic Am ${ }^{\text {III }}$ complexes with TODGA and $\mathrm{SO}_{3}-\mathrm{Ph}-\mathrm{BTP}^{4-}$, which we formulated independently [38].

Recently, Harwood and coworkers modified the phenanthroline backbone of $\mathrm{CyMe}_{4}-\mathrm{BTPhen}$ ligand by attaching either bromo- or hydroxyphenyl- substituents, which made the ligand more selective for $\mathrm{Am}^{\mathrm{III}}$ over $\mathrm{Cm}^{\mathrm{IIII}}$. The reported $\mathrm{SF}_{\mathrm{Am} / \mathrm{Cm}}$ values up to $\sim 7$ or $\sim 5$ for the $5-\mathrm{Br}$ and 5-(4-hydroxyphenyl) substituted ligands, respectively, unfortunately 
at low or moderate $\mathrm{HNO}_{3}$ concentrations [56], give a chance to further improve the $A m^{\text {III }}$-selectivity of the system when combining these extractants with a $\mathrm{Cm}^{\mathrm{III}}$-selective hydrophilic ligand in the aqueous phase.

\section{CONCLUSIONS}

Novel solvent extraction methods of separation of trivalent minor actinides from liquid nuclear wastes, developed in European laboratories, have been reviewed and discussed. A special attention was put on the separation of americium(III) from the lanthanide fission products as well as from curium. Numerous actinide-selective ligands efficient in strongly acidic two-phase systems, both lipophilic extractants and hydrophilic complexants (the latter for masking or for selective stripping of minor actinides), were synthesized and tested. Various separation processes have been developed and demonstrated with genuine high-level nuclear wastes in batteries of centrifugal contactors. The separation of americium(III) alone from the PUREX or COEX raffinates is the process of particular interest.

The most appropriate hydrometalurgical methods of advanced reprocessing of spent nuclear fuel, directed on the closed fuel cycle, are expected to be soon matured and implemented in nuclear technologies. This should significantly increase the level of energy production from the same uranium resources and minimize the formation of high-level nuclear wastes, making the nuclear power more sustainable and safe.

\section{ACKNOWLEDGEMENT}

This paper has been prepared within the statutory research of the Institute of Nuclear Chemistry and Technology. It is based on the author's expertise gained as a result of his participation in the consecutive integrated and collaborative FP6 and FP7 Euratom projects: EUROPART, ACSEPT and SACSESS, which is kindly acknowledged. 


\section{REFERENCES}

[1] P. A. Baisden and C. E. Atkins-Duffin, in „Handbook of Nuclear Chemistry”, Second Edition (A. Vértes, S. Nagy, Z. Klencsár, R.G. Lovas, F. Rösch, Eds.), Springer, vol. 7, pp. 2797-2835, (2011).

[2] „Fast Reactor Technology: A Path to Long-Term Energy Sustainability", Position Statement \#74, November 2005, American Nuclear Society, www.ans.org.

[3] C. Poinssot, C. Rostaing, S. Grandjean and B. Boullis, Procedia Chem., 7, 349-357, (2012).

[4] F. Drain, J. L. Emin, R. Vinoche, P. Baron, Proc. Waste Management Symposium 2008, Tucson, AZ.

[5] M. Salvatores and G. Palmiotti, Prog. Part. Nucl. Phys., 66, 144-166, (2011).

[6] „Trends towards Sustainability in the Nuclear Fuel Cycle”, NEA No. 6980, ISBN 978-92-64-16810-7, OECD-NEA (2011).

[7] S. Bourg, C. Hill, C. Caravaca, C. Rhodes, C. Ekberg, R. Taylor, A. Geist, G. Modolo, L. Cassayre, R. Malmbeck, M. Harrison, G. de Angelis, A. Espartero, S. Bouvet and N. Ouvrier, Nucl. Eng. Design, 241, 3427-3435, (2011).

[8] S. Bourg, A. Geist and J. Narbutt, Nukleonika, 60, 809-814, (2015).

[9] T. Koyama, Y. Sakamura, M. lizuka, T. Kato, T. Murakami and J.-P. Glatz, Procedia Chem.,7, 772-778, (2012).

[10] D. Rodrigues, G. Durán and S. Delpech, Nukleonika, 60, 907-914, (2015).

[11] Z. Kolarik, Chem. Rev., 108, 4208-4252, (2008).

[12] C. Hill, in „Ion Exchange and Solvent Extraction: A Series of Advances”, (B. A. Moyer, Ed.), CRC Press, vol. 19, pp. 119-193, (2010).

[13] P. J. Panak and A. Geist, Chem. Rev., 113, 1199-1236, (2013).

[14] A. Bhattacharyya, P. K. Mohapatra and V. K. Manchanda, Solvent Extr. Ion Exch., 24, 1-17, (2006).

[15] Z. Kolarik, U. Müllich and F. Gassner, Solvent Extr. Ion Exch., 17, 23-32, (1999).

[16] M. J. Hudson, C. Boucher, D. Braekers, J. F. Desreux, M. G. B. Drew, M. R. St. J. Foreman, L. M. Harwood, C. Hill, C. Madic, F. Marken and T. G. A. Youngs, New J. Chem., 30, 1171-1183, (2006). 
[17] M. G. B. Drew, M. R. St. J. Foreman, C. Hill, M. J. Hudson and C. Madic, Inorg. Chem. Commun., 8, 239-241, (2005).

[18] M. R. S. Foreman, M. J. Hudson, M. G. B. Drew, C. Hill and C. Madic, Dalton Trans. 1647-1653, (2006).

[19] A. Geist, C. Hill, G. Modolo, M. R. S. Foreman, M. Weigl, K. Gompper, M. J. Hudson and C. Madic, Solvent Extr. Ion Exch., 24, 463-483, (2006).

[20] G. Modolo, A. Wilden, H. Daniels, A. Geist, D. Magnusson and R. Malmbeck, Radiochim. Acta, 101, 155-162, (2013).

[21] E. Aneheim, C. Ekberg, A. Fermvik, M. R. S. Foreman, T. Retegan and G. Skarnemark, Solvent Extr. Ion Exch., 28, 437-458, (2010).

[22] J. Narbutt and J. Krejzler, Radiochim. Acta, 96, 219-223, (2008).

[23] G. Modolo, A. Wilden, A. Geist, D. Magnusson and R. Malmbeck, Radiochim. Acta, 100, 715-725, (2012).

[24] D. Magnusson, B. Christiansen, M. R. S. Foreman, A. Geist, J-P. Glatz, R. Malmbeck, G. Modolo, D. Serrano-Purroy and C. Sorel, Solvent Extr. Ion Exch., 27, 97-106, (2009).

[25] D. Magnusson, B. Christiansen, J-P. Glatz, R. Malmbeck, G. Modolo, D. Serrano-Purroy and C. Sorel, Radiochim. Acta, 97, 155-159, (2009).

[26] F. W. Lewis, L. M. Harwood, M. J. Hudson, M. G. B. Drew, J. F. Desreux, G. Vidick, N. Bouslimani, G. Modolo, A. Wilden, M. Sypula, T.-H. Vu and J.-P. Simonin, J. Am. Chem. Soc., 133, 13093-13102, (2011),

[27] F. W. Lewis, L. M. Harwood, M. J. Hudson, M. G. B. Drew, V. Hubscher-Bruder, V. Videva, F. Arnaud-Neu, K. Stamberg and S. Vyas, Inorg. Chem., 52, 4993-5005, (2013).

[28] K. Lyczko and S. Ostrowski, Nukleonika, 60, 853-857, (2015).

[29] A. Wilden, C. Schreinemachers, M. Sypula and G. Modolo, Solvent Extr. Ion Exch., 29, 190-212, (2011).

[30] A. Wilden, G. Modolo, C. Schreinemachers, F. Sadowski, S. Lange, M. Sypula, D. Magnusson, A. Geist, F. W. Lewis, L. M. Harwood and M. J. Hudson, Solvent Extr. Ion Exch., 31, 519-537, (2013).

[31] M. J. Hudson, L. M. Harwood, D. M. Laventine and F. W. Lewis, Inorg. Chem., 52, 3414-3428, (2013).

[32] J. Narbutt and W. P. Oziminski, Dalton Trans., 41, 14416-14424, (2012).

[33] J. Narbutt, A. Wodyński and M. Pecul, Dalton Trans., 44, 26572666, (2015). 
[34] C.-L. Xiao, C.-Z. Wang, J.-H. Lan, L.-Y. Yuan, Y.-L. Zhao, Z.-F. Chai and W.-Q. Shi, Radiochim. Acta, 102, 875-886, (2014).

[35] A. Geist, U. Müllich, D. Magnusson, P. Kaden, G. Modolo, A. Wilden and T. Zevaco, Solvent Extr. Ion Exch., 30, 433-444, (2012).

[36] A. Wilden, G. Modolo, P. Kaufholz, F. Sadowski, S. Lange, M. Sypula, D. Magnusson, U. Müllich, A. Geist and D. Bosbach, Solvent Extr. Ion Exch., 33, 91-108, (2015).

[37] C. M. Ruff, U. Müllich, A. Geist and P. J. Panak, Dalton Trans., 41, 14594-14602, (2012).

[38] Ł. Steczek, M. Rejnis, J. Narbutt, M.-C. Charbonnel, P. Moisy, J. Radioanal. Nucl. Chem., (2016), DOI 10.1007/s10967-0154663-7.

[39] [39] L. Steczek, J. Narbutt, M.-C. Charbonnel, P. Moisy, Nukleonika, 60, 821-827, (2015).

[40] F. W. Lewis, L. M. Harwood, M. J. Hudson, A. Geist, V. N. Kozhevnikov, P. Distler and J. John, Chem Sci. 6, 48124821, (2015).

[41] P. Kaufholz, F. Sadowski, A. Wilden, G. Modolo, F. W. Lewis, A. W. Smith and L. M. Harwood, Nukleonika, 60, 815-820, (2015).

[42] S. Scaravaggi, E. Macerata, M. Galletta, M. Mossini, A. Casnati, M. Anselmi, F Sansone and M. Mariani, J. Radioanal. Nucl. Chem., 303, 1811-1820, (2015).

[43] M. Heitzmann, C. Gateau, L. Chareire, M. Miguirdithian, M.-C. Charbonnel and P Delangle, New J Chem. 34:108-116, (2010).

[44] J. Borrini, A. Favre-Reguillon, M. Lemaire, S. Gracia, G. Arrachart, G. Bernier, X. Hérès, C. Hill and S. Pellet-Rostaing, Solvent Extr Ion Exch. 33:224-235, (2015).

[45] J. Brown, F. McLachlan, M. Sarsfield, R. Taylor, G. Modolo and A. Wilden, Solvent Extr. Ion Exch., 30, 127-141, (2012).

[46] M. Carrott, K, Bell, J. Brown, A. Geist, C. Gregson, X. Hérès, Ch. Maher, R. Malmbeck, Ch. Mason, G. Modolo, U. Müllich, M. Sarsfield, A. Wilden and R. Taylor, Solvent Extr. Ion Exch., 32, 447-467, (2014). 
[47] M. Carrott, A. Geist, C. Gregson, X. Hérès, S. Lange, R. Malmbeck, M. Miguirditchian, G. Modolo, A. Wilden and R. Taylor, Hydrometallurgy, 152, 139-148, (2015).

[48] C. Poinssot, C. Rostaing, P. Baron, D. Warin and B.Boullis, Procedia Chem., 7, 358-366, (2012).

[49] C. Rostaing, C. Poinssot, D. Warin, P. Baron and B. Lorrain, Procedia Chem., 7, 367-373, (2012).

[50] W. H. Runde and B. J. Mincher, Chem. Rev., 111, 5723-5741, (2011).

[51] G. Modolo and S. Nabet, Solvent Extr. Ion Exch., 23, 359-373, (2005).

[52] G. Modolo, P. Kluxen and A. Geist, Radiochim. Acta, 98, 193-201, (2010).

[53] M.-C. Charbonnel, C. Berthon, C. Berthon, N. Boubals, F. Burdet, M.-T. Duchesne, P. Guilabaud, N. Mabille, S. Petit and N. Zorz, Procedia Chem., 7, 20-26, (2012).

[54] S. Chapron, C. Marie, G. Arrachart, M. Miguirditchian and S. Pellet-Rostaing, Solvent Extr. Ion Exch., 33, 236-248, (2015).

[55] V. Pacary, F. Burdet and M.-T. Duchesne, Procedia Chem., 7, 328-333, (2012).

[56] A. Afsar, L. M. Harwood, M. J. Hudson, J. Westwood and A. Geist, Chem. Commun., 51, 5860-5863, (2015). 